\section{Practitioners' perspectives and experiences of the new National Health Service dental contract}

\author{
I. G. Chestnutt, ${ }^{1}$ L. Davies ${ }^{2}$ and D. R. Thomas ${ }^{3}$
}

VERIFIABLE CPD PAPER
IN BRIEF

- Examines the perspectives and experiences of general dental practitioners in Wales 18 months after the introduction of the new contract.

- Provides an appraisal of the impact of the contract.

- In the eyes of the majority of practitioners, the contract failed to deliver many of its objectives as set out by the Department of Health in England and endorsed by the Wales Assembly Government.

\begin{abstract}
Background In April 2006, fundamental changes were made to the arrangements for commissioning state funded (National Health Service, NHS) dental care in England and Wales. These involved the dissolution of a universal national contract and the introduction of locally commissioned primary dental care services. Suggested advantages included the elimination of a fee-for-item 'treadmill', an increased emphasis on prevention and improved patient access. This change came at a time when many practitioners were opting to provide care outside the NHS. Objectives This study investigated dentists' experience of the new contract and compared this with attitudes determined in a previous survey of the same cohort of dentists conducted immediately before the changed commissioning arrangements. Methods Data were collected via a postal questionnaire, comprising a combination of 60 open and closed questions, mailed to 608 general dental practitioners in Wales. Results Four hundred and ninety-six (77\%) questionnaires were returned. Four hundred and seventeen practitioners continued to provide NHS dental care. Only 46 (11\%) of the 417 practitioners agreed that they liked the new method of remuneration and the majority (362 [86.8\%]) perceived that they still delivered state-funded care in a 'treadmill' environment. This compares with $34.9 \%$ of dentists who perceived the new system as a 'treadmill' immediately before its implementation. Three hundred and forty-eight (83.4\%) disagreed that they were able to spend more time on prevention and $356(85.3 \%)$ did not feel they had more time to spend with patients - key objectives of the reforms. Two hundred and seventy-five (65.9\%) respondents agreed that local NHS commissioners were controlling their business. Conclusion This survey, conducted 18 months after the implementation of the new commissioning arrangements, suggests that practitioners are deeply unhappy with local commissioning. It raises questions as to whether the changes have achieved the Government's stated objectives in reforming state-funded primary dental care.
\end{abstract}

\section{INTRODUCTION}

A series of Government and independent reports throughout the 1980s, 1990s and early 2000s considered National Health Service (NHS) primary dental care services and the arrangements for commissioning care from independent general dental practitioners (GDPs). ${ }^{1-5}$ This body of work concluded that the then existing, national, fee-for-item of service system was outdated and in need of reform. In England and Wales, this lead

${ }_{1}$ Professor and Honorary Consultant in Public Dental Health, ${ }^{2}$ Research Associate, Dental Public Health Unit, Cardiff University Dental School, Heath Park, Cardiff, CF14 4XY; ${ }^{3}$ Consultant in Dental Public Health, National Public Health Service for Wales, Mamhilad House, Mamhilad Park Estate, Pontypool, NP4 OYP

${ }^{*}$ Correspondence to: Professor Ivor G. Chestnutt Tel: +44 (0)292074 6680; Fax: +44 (0)29 20746489 Email: chestnuttig@ cardiff.ac.uk

\section{Online article number E18}

Refereed Paper - accepted 28 November 2008

DOI: $10.1038 /$ sj.bdj.2009.354

${ }^{\circledR}$ British Dental Journal 2009; 206: E18 to the introduction of a new contract on 1 April 2006, arguably the greatest change in state funded dental care since the inception of the NHS in 1948.

The national, largely fee-for-item of service contract was replaced by locally commissioned dental care. Under these arrangements local health bodies (primary care trusts in England, local health boards in Wales), were required to contract directly with dental care providers. The stated objectives of the new contract were to: ${ }^{6}$

- Commission dental services locally

- Improve access to service for NHS patients

- Remove the item of service 'treadmill' which many dentists perceived they were working

- Encourage fewer interventions, freeing up time for a more preventive approach

- Make NHS dentistry more attractive to dentists and improve the quality of dentists' working lives

- Introduce a simplified system of patient charges.

It is obviously important from the perspective of the commissioners, providers and consumers of dental care, to investigate dentists' perceptions of whether the new contract is meeting the objectives of the reforms.

Milsom and colleagues have reported a qualitative investigation of dentists' and primary care trust dental leads' views on the new contract immediately prior to its inception in England.7 They concluded that at that early stage, there were a number of concerns about the new contract: it was not perceived as being necessary, it was implemented at speed with insufficient negotiation and it was viewed as being untested. In Wales, Chestnutt and co-workers ${ }^{8}$ investigated 
dentists' perceptions and attitudes to the new contract in the three months immediately prior to its inception. They too found that at that time, dentists expressed considerable concern over the ability of the new commissioning arrangements to remove the treadmill or deliver a more preventively orientated service. However, both of these studies were based on what dentists and commissioners thought they were about to experience.

The current study investigated Welsh dentists' experience of the new contract 18 months following implementation. The study objectives were:

- To report changes in practitioners' commitment to the NHS since the introduction of the new contract and factors associated with NHS commitment

- To investigate practitioners' intentions with regards to the provision of NHS general dental services beyond April 2009

- To examine practitioners' perceptions of the new contract and its impact on - Their practice

- Their patients

- The treatments they now offer

- To determine satisfaction with practitioners' current working environment

- To compare practitioners' experience of the new contract 18 months following implementation, with their expectations stated in the period immediately prior to its implementation.

\section{MATERIAL AND METHODS}

\section{The participants}

The sample frame comprised all 608 general dental practitioners in Wales who had responded to the baseline 2006 survey $^{8}$ and who were at that time providing NHS dental services.

\section{The questionnaire}

Data were collected using a selfadministered postal questionnaire. This contained 57 items and a combination of open and closed questions were posed. In addition to questions on demographic variables (gender, time since qualification), respondents were asked about past, present

Table 1 Percentage agreement with general statements relating to the impact of the new contract

\begin{tabular}{|c|c|c|c|c|}
\hline Statement & $\begin{array}{l}\text { Strongly } \\
\text { agree/ } \\
\text { Agree }\end{array}$ & $\begin{array}{l}\text { Neither } \\
\text { agree nor } \\
\text { disagree }\end{array}$ & $\begin{array}{l}\text { Disagree/ } \\
\text { Strongly } \\
\text { disagree }\end{array}$ & $\begin{array}{l}\text { Not } \\
\text { answered }\end{array}$ \\
\hline $\begin{array}{l}\text { The lack of out of hours commitment } \\
\text { appeals to me }\end{array}$ & 71.7 & 17.9 & 9.8 & 0.5 \\
\hline The LHB is controlling my business & 65.9 & 23.0 & 10.5 & 0.5 \\
\hline $\begin{array}{l}\text { There is still ambiguity about mixing } \\
\text { private and NHS work }\end{array}$ & 52.7 & 31.8 & 14.4 & 0.9 \\
\hline $\begin{array}{l}\text { I currently provide NHS dental services } \\
\text { because I feel I have no other choice }\end{array}$ & 48.9 & 27.3 & 22.3 & 1.4 \\
\hline I am able to provide NHS and private dentistry & 46.7 & 35.4 & 15.8 & 1.9 \\
\hline $\begin{array}{l}\text { Corporate providers have impacted } \\
\text { on my practice }\end{array}$ & 30.4 & 28.0 & 40.0 & 1.4 \\
\hline There is flexibility in the hours I choose to work & 25.8 & 30.7 & 42.2 & 1.2 \\
\hline There is less administration & 16.5 & 20.3 & 61.6 & 1.4 \\
\hline I am my own boss & 15.3 & 23.3 & 59.9 & 1.4 \\
\hline I like contracting locally with the LHB & 14.8 & 32.8 & 51.3 & 0.9 \\
\hline
\end{tabular}

Table 2 Percentage agreement with statements relating to financial aspects of the new contract

\begin{tabular}{|l|l|l|l|l}
\hline Statement & $\begin{array}{l}\text { Strongly } \\
\text { agree/ } \\
\text { Agree }\end{array}$ & $\begin{array}{l}\text { Neither } \\
\text { agree nor } \\
\text { disagree }\end{array}$ & $\begin{array}{l}\text { Disagree/ } \\
\text { Strongly } \\
\text { disagree }\end{array}$ & $\begin{array}{l}\text { Not } \\
\text { answered }\end{array}$ \\
\hline The UDA bands are too wide & 87.0 & 8.1 & 3.1 & 1.6 \\
\hline The UDA system of remuneration is a treadmill & 86.8 & 4.3 & 7.4 & 1.4 \\
\hline $\begin{array}{l}\text { I fear being penalised financially if } \\
\text { my activity falls }\end{array}$ & 83.2 & 7.7 & 7.9 & 1.2 \\
\hline $\begin{array}{l}\text { The inability to charge for broken } \\
\text { appointments has impacted on my practice. }\end{array}$ & 75.5 & 14.4 & 9.3 & 0.7 \\
\hline $\begin{array}{l}\text { It has been difficult and time } \\
\text { consuming explaining patient charges }\end{array}$ & 41.9 & 31.6 & 22.5 & 3.8 \\
\hline $\begin{array}{l}\text { There has been an increase in } \\
\text { complaints about patient charges }\end{array}$ & 36.2 & 33.8 & 25.6 & 4.3 \\
\hline $\begin{array}{l}\text { The guaranteed gross income for } \\
3 \text { years appeals to me }\end{array}$ & 32.8 & 33.1 & 33.1 & 0.9 \\
\hline $\begin{array}{l}\text { NICE recall guidelines have substantially } \\
\text { affected the income of my practice }\end{array}$ & 11.3 & 43.4 & 43.6 & 1.6 \\
\hline \begin{tabular}{l} 
I like the new method of remuneration \\
\hline I like the new patient charges
\end{tabular} & 11.0 & 16.3 & 71.7 & 0.9 \\
\hline $\begin{array}{l}\text { UDAs are a better method remuneration } \\
\begin{array}{l}\mathrm{n}=417 \\
\hline\end{array}\end{array}$ & 10.5 & 17.7 & 70.0 & 1.7 \\
\hline
\end{tabular}

and future NHS commitment. A series of attitudinal statements were posed. These covered:

- General issues relating to the introduction of the contract

- Financial aspects of the contract

- The impact of the contract on patients

- The impact of the contract on treatment provision

- The current working environment.
The respondents were asked on a five-point Likert scale to indicate whether they strongly agreed, agreed, neither agreed or disagreed, disagreed, or strongly disagreed with these given statements.

Many of the questions were identical to those posed in the previous survey. ${ }^{8}$ The questions selected were designed to gain an understanding of why 
participants continued to deliver NHS dentistry, perceptions of their current working environment and experience of the new contract. With regards to the latter, questions covered in particular detail issues relating to the financial aspects of the contract, its implementation and treatment provision.

As all of the questions used had been part of the previous survey, no pilot of the questionnaire was considered necessary, albeit some of the wording of the questions had been changed in tense in recognition of pre- and post-implementation phases of contract implementation.

Respondents were identified only by codes.

\section{Data collection}

The main mailing was conducted in November 2007 and was accompanied by an explanatory letter and prepaid reply envelope. Non-respondents were sent a further questionnaire in early January 2008.

\section{Data analysis}

Completed questionnaires were coded and entered into a database and analysed by SPSS v12 (Chicago, Illinois). Frequencies were used to examine the distribution of the responses for all variables and describe sample demographics. The association between variables was examined by cross-tabulations and the statistical significance of such relationships were determined by Chi-square analysis.

\section{RESULTS}

\section{Demographics of survey respond- ents and current NHS commitment}

Of the 608 questionnaires mailed, 469 $(77 \%)$ were returned. Of these, 417 were from practitioners who continued to provide NHS dental services. All 608 practitioners to whom the questionnaire was sent had been providing NHS dental services at the time of the January 2006 survey. Of the 52 no longer providing NHS dental services, 28 (6\%) had decided to provide only private dentistry, $10(2.1 \%)$ claimed they were unable to negotiate a suitable contract, 12 (2.5\%) had retired and two had opted out of the NHS for some other reason.
In the case of the 417 who continued to provide NHS dental services, just over half $(253,53.9 \%)$ reported doing so at the same level as before the introduction of the new contract. Almost one quarter (111, 23.7\%) indicated that while continuing to provide NHS dental services, they had decreased their commitment to the NHS. In contrast 34 (7.2\%) had increased their commitment.

The survey participants were also asked about wanting to change their NHS commitment. A total of 124 (29.7\%) dentists indicated that they had wanted to increase their commitment but had been unable to do so. On the other hand, 57 (13.6\%) said that they had wanted to decrease their NHS commitment but been unable to achieve this objective.

Respondents were asked if they worked as providers or performers under the new contract. In response $45.5 \%$ said they were providers, $37.5 \%$ were performers and a further 16.5\% described themselves are providers/performers, this classification being missing for $1.6 \%$ of respondents.

\section{The effect of gender and time since qualification on working practices}

Just under $70 \%$ of those providing NHS dental services were male (291 males: 125 females). Females were significantly more likely ( $p<0.001$ ) to work for three days per week or less $-32 \%$ of the 125 respondents compared with $7.2 \%$ of their male counterparts. On the other hand, while $68 \%$ of women worked for more than three days per week, $92.8 \%$ of males were in this category.

Dentists who qualified before 1986, the median time since qualification, were significantly more likely $(p<0.01)$ to indicate that they worked for three days per week or less than those who qualified in 1986 or later. Although not statistically significant, it is also of note that while $32 \%$ of the most recently qualified quartile (1995 or later) devoted 99-100\% of their time to the NHS, in the longest qualified quartile this fell to $21 \%$. This trend reflects the fact that as dentists progress in their careers they are more likely to work part-time and to devote less time to the NHS.

\section{Future commitment to the NHS}

Plans with regards to NHS provision once the period of guaranteed income protection expires in April 2009 were also investigated. While one-third of respondents indicated they would continue to provide NHS services beyond April 2009, 29 (6.9\%) said that they would not. The majority, 244 (58.5\%), were undecided.

\section{General contract issues}

Shown in Table 1 is the dentists' agreement with a series of general statements that relate to the new contract, ordered according to those with which the dentists most strongly agreed. The majority (71.7\%) welcomed the lack of out-ofhours commitment resulting from the new contract. Just over half felt that there was ambiguity about mixing private and NHS work and a similar number (204, 48.9\%) agreed that they currently provided NHS dental services because they felt they had no other choice. The impact of corporate providers on practices was agreed by 127 (30.4\%). Only $16.5 \%$ of the dentists thought that the new contract involved less administration and just 62 (14.8\%) agreed that they liked contracting locally with the local health board (LHB).

\section{Financial aspects of the new contract}

Table 2 presents agreement with a series of statements relating to the financial aspects of the new contract and how they have impacted on practice. Statements are ordered by the percentage of dentists agreeing. The great majority (363, 87\%) thought the unit of dental activity (UDA) bands* were too wide and a similar number agreed the UDA system of remuneration is a 'treadmill'. Only 29 (6.9\%) dentists viewed the UDA as a better method of remuneration than the previously existing fee-for-item system. Fear of being penalised for falling activity levels was agreed by 347 (83.2\%). The appeal of a guaranteed gross income for three years elicited a mixed response.

*Units of dental activity (UDA) are the currency used in contracting with dentists. Courses of treatment are defined in three bands relating to the complexity of the treatment provided. 


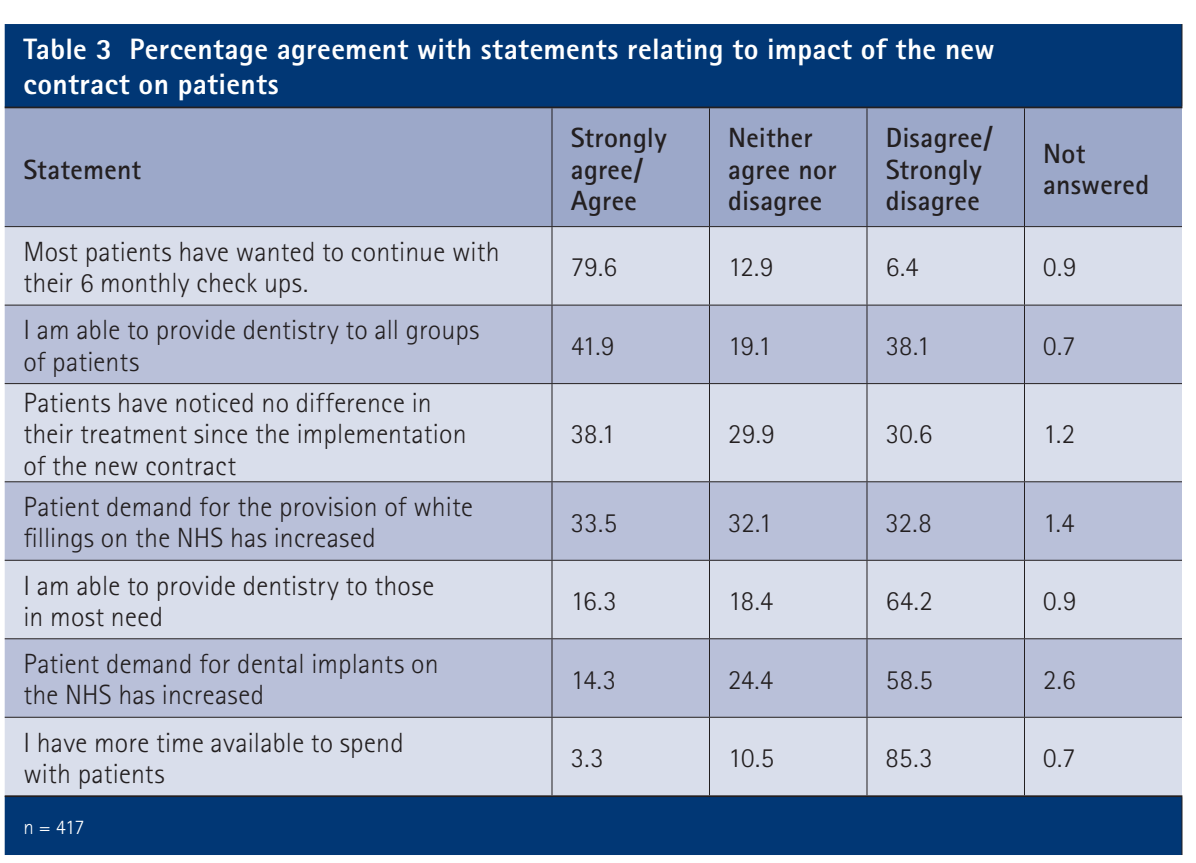

Table 4 Percentage agreement with statements relating to impact of the new contract on treatment provision

\begin{tabular}{|c|c|c|c|c|}
\hline Statement & $\begin{array}{l}\text { Strongly } \\
\text { agree/ } \\
\text { Agree }\end{array}$ & $\begin{array}{l}\text { Neither } \\
\text { agree nor } \\
\text { disagree }\end{array}$ & $\begin{array}{l}\text { Disagree/ } \\
\text { Strongly } \\
\text { disagree }\end{array}$ & $\begin{array}{l}\text { Not } \\
\text { answered }\end{array}$ \\
\hline I apply the NICE guidelines on recall & 50.3 & 31.8 & 17.0 & 0.7 \\
\hline I have freedom in clinical decisions & 24.2 & 29.0 & 45.5 & 1.2 \\
\hline $\begin{array}{l}\text { I am able to prioritise treatments for } \\
\text { children and exempt patients }\end{array}$ & 21.8 & 22.3 & 54.6 & 1.2 \\
\hline $\begin{array}{l}\text { Outmoded treatment incentives have } \\
\text { been removed }\end{array}$ & 14.8 & 26.8 & 57.0 & 1.2 \\
\hline $\begin{array}{l}\text { I have introduced innovations such } \\
\text { as smoking cessation }\end{array}$ & 12.2 & 24.2 & 61.8 & 1.7 \\
\hline $\begin{array}{l}\text { The new contract allows me to provide } \\
\text { a good quality of care }\end{array}$ & 11.9 & 24.4 & 62.5 & 1.6 \\
\hline $\begin{array}{l}\text { The new contract allows me to provide } \\
\text { a range of treatments }\end{array}$ & 8.6 & 18.9 & 71.7 & 0.7 \\
\hline $\begin{array}{l}\text { I am able to provide a wider range } \\
\text { of treatments }\end{array}$ & 4.8 & 8.4 & 85.8 & 0.9 \\
\hline I am able to spend more time on prevention & 3.6 & 12.4 & 83.4 & 0.5 \\
\hline
\end{tabular}

The inability to charge patients for broken appointments had impacted on the practices of $315(75.5 \%)$ respondents. Views were mixed on whether there had been an increase in complaints about patient charges. Just 44 (10.5\%) agreed that they liked the new patient charge arrangements. Only $46(11 \%)$ agreed that they liked the new method of remuneration.

\section{Dentists' perception of the impact of the new contract on patients}

Perceptions of the impact of the new contract on patients are illustrated in Table

\section{Dentists' perceptions of the new contract on treatment provision}

Perception of the new contract on treatment provision is illustrated in Table 4, ordered by the percentage of dentists agreeing with the given statements.

Just over half $(210,50.3 \%)$ agreed that they were able to apply the NICE guidelines $^{9}$ on recall intervals.** However, just one quarter $(101,24.2 \%)$ felt they had freedom in clinical decisions under the new contract, with fewer $(91,21.8 \%)$ agreeing that they were able to prioritise treatment for children and exempt patients. Only $14.8 \%$ agreed that the new contract had removed outmoded treatment incentives. While $12.2 \%$ claimed to have introduced innovations such as smoking cessation advice, only 15 (3.6\%) dentists agreed that they were now able to spend more time on prevention. Good quality care provision under the new contract was agreed by $50(11.9 \%)$ of those responding.

\section{Dentists' perceptions of their current working environment}

The survey respondents were asked a series of questions relating to their current working environment. Responses are shown in Table 5. These suggest that the majority are in agreement that the clinical facilities available to them are good and only a minority were in disagreement over equipment and materials at their disposal, the environment or the level of clinical support. A greater degree of dissatisfaction was evident with regard to levels of information technology (IT) provision or non-clinical staff support. The issues with which there was least agreement centred around having enough time for continuing professional development, clinical governance/audit and administrative work.

3. The majority of dentists are in agree ment that most patients have wanted to continue with their six-monthly 'checkup'. Views were mixed on whether patients had noticed a difference in their treatment since the implementation of the new contract, $38.1 \%$ agreeing that patients had not noticed a difference. A minority, 68 (16.3\%), agreed that they were able to provide dentistry to those in most need. Just 14 (3.3\%) agreed that under the new contract they had more time available to spend with patients.

\section{Comparison of survey responses immediately pre- and 18 months post-contract implementation}

A comparison of key elements of the contract pre-contract implementation in January $2006^{8}$ and after 18 months in November 2007 are presented in Table 6.

**The NICE guidelines on recall intervals suggest that the frequency of dental attendance should be determined on disease-risk of individual patients. For adults this ranges from 3-24 months. 
It is apparent that in the period immediately prior to the implementation of the reforms there was great concern over the changed patient charges. However, complaints in this area have not been as great as practitioners feared, although $41.9 \%$ in the second survey agreed that it has been difficult and time consuming explaining patient charges.

There was a marked reduction in the percentage of dentists agreeing that they 'are their own boss' (63\% to 15.3\%) and in the flexibility in the hours they choose to work (69.6\% to $25.8 \%$ ). However, the reduction in those agreeing their 'work-life balance is good' was less marked (36.5\% to $26.4 \%$ ).

The reduction in those agreeing that they can provide dentistry to all groups of patients (63.7\% to $41.9 \%$ ) to those in most need (43.6\% to $16.3 \%)$ are in stark contrast to what it was hoped the new dental contract would achieve. What is particularly of note are the responses to the statement about having more time available to spend with patients on prevention. While in the run-up to the implementation of the new dental contract 23\% said that they were tempted by having more time available to spend with patients, 18 months later just 3.3\% agreed this to be the case. The corresponding percentages relating to time to spend on prevention are $19.4 \%$ and 3.6\%.

While $34 \%$ agreed that they wanted to change from the perceived 'item of service treadmill', a remarkable $86.8 \%$ of those replying to the second survey thought that the UDA system was a 'treadmill'.
On a more positive note, in the second survey $50.3 \%$ agreed that they can apply the NICE guidelines ${ }^{9}$ on recall intervals compared with the $28.3 \%$ who made this claim in January 2006.

\section{DISCUSSION}

The response rate to this survey was excellent, with $77 \%$ of those questioned

\begin{tabular}{|c|c|c|c|c|}
\hline Statement & $\begin{array}{l}\text { Strongly } \\
\text { agree/ } \\
\text { Agree }\end{array}$ & $\begin{array}{l}\text { Neither } \\
\text { agree nor } \\
\text { disagree }\end{array}$ & $\begin{array}{l}\text { Disagree/ } \\
\text { Strongly } \\
\text { disagree }\end{array}$ & $\begin{array}{l}\text { Not } \\
\text { answered }\end{array}$ \\
\hline $\begin{array}{l}\text { The equipment/materials at my disposal } \\
\text { are good }\end{array}$ & 59.2 & 26.3 & 13.4 & 0.9 \\
\hline I am happy with the surgery environment & 53.2 & 27.8 & 18.2 & 0.7 \\
\hline There is adequate clinical staff support & 52.0 & 32.6 & 14.3 & 0.9 \\
\hline $\begin{array}{l}\text { The level of IT provision in my practice } \\
\text { is adequate }\end{array}$ & 47.9 & 18.4 & 30.9 & 2.6 \\
\hline There is adequate non-clinical staff support & 43.8 & 34.5 & 20.3 & 1.2 \\
\hline My current work-life balance is good & 26.4 & 28.5 & 44.4 & 0.7 \\
\hline I have enough time for CPD & 19.9 & 25.1 & 54.2 & 0.7 \\
\hline I have enough time for administrative work & 15.3 & 20.8 & 63.0 & 0.7 \\
\hline $\begin{array}{l}\text { I have enough time for clinical } \\
\text { governance/audit }\end{array}$ & 14.1 & 21.6 & 63.3 & 0.9 \\
\hline
\end{tabular}

Table 6 The percentage of respondents agreeing with attitudinal statements in (a) the survey conducted in January 2006 (pre-contract) 8 and November 2007 (post-contract)

Statements with which dentists were asked to agree (a) in the Jan 2006 (pre-contract survey) and (b) in Nov 2007 (18 month post-implementation survey)

(a) I will be able to provide dentistry to all groups of patients (b) I am able to provide dentistry to all patient groups

(a) \& (b) I am able to provide dentistry to those in most need

(a) \&t (b) I am my own boss

(a) $\&$ (b) There is flexibility in the hours I choose to work

(a) \&t (b) The level of IT provision in my practice is adequate

(a) \& (b) My current work-life balance is good

(a) I am tempted by more time available to spend with patients

(b) I have more time available to spend with patients

(a) I want to change from the fee for item of service treadmill

(b) The UDA system of remuneration is a treadmill

(a) I can apply the NICE guidelines on recall

(b) I apply the NICE guidelines on recall

(a) Outmoded treatment incentives will be removed

(b) Outmoded treatment incentives have been removed

(a) I will be able to spend more time on prevention

(b) I have been able to spend more time on prevention

(a) There will be an increase in complaints about patient charges

(b) There has been an increase in complaints about patient charges

\begin{tabular}{|c|c|c|c|c|c|}
\hline \multicolumn{2}{|c|}{$\begin{array}{l}\text { Strongly agree/agree } \\
(\%)^{\circ}\end{array}$} & \multicolumn{2}{|c|}{$\begin{array}{l}\text { Neither disagree } \\
\text { nor agree }(\%)\end{array}$} & \multicolumn{2}{|c|}{$\begin{array}{l}\text { Strongly disagree/ } \\
\text { disagree }(\%)\end{array}$} \\
\hline $\begin{array}{l}\text { (a) } 2006 \\
n=608\end{array}$ & $\begin{array}{l}\text { (b) } 2007 \\
n=417\end{array}$ & $\begin{array}{l}\text { (a) } 2006 \\
n=608\end{array}$ & $\begin{array}{l}\text { (b) } 2007 \\
n=417\end{array}$ & $\begin{array}{l}\text { (a) } 2006 \\
n=608\end{array}$ & $\begin{array}{l}\text { (b) } 2007 \\
n=417\end{array}$ \\
\hline 63.7 & 41.9 & 16.6 & 19.1 & 17.6 & 38.1 \\
\hline 43.6 & 16.3 & 28.5 & 18.4 & 25.7 & 64.2 \\
\hline 63.0 & 15.3 & 18.8 & 23.3 & 15.1 & 59.9 \\
\hline 69.6 & 25.8 & 16 & 30.7 & 12.7 & 42.2 \\
\hline 47.4 & 47.9 & 16.3 & 18.4 & 34 & 30.9 \\
\hline 36.5 & 26.4 & 27.8 & 28.5 & 34.5 & 44.4 \\
\hline 23.0 & 3.3 & 16.1 & 10.5 & 58.6 & 85.3 \\
\hline 34.9 & 86.8 & 22.2 & 4.3 & 39.6 & 7.4 \\
\hline 28.3 & 50.3 & 33.4 & 31.8 & 34.5 & 17.0 \\
\hline 22.4 & 14.8 & 27.6 & 26.8 & 45.4 & 57.0 \\
\hline 19.4 & 3.6 & 18.3 & 12.4 & 59.4 & 83.4 \\
\hline 72.2 & 36.2 & 15.5 & 33.8 & 10.0 & 25.6 \\
\hline
\end{tabular}

*Responses may not total 100\% due to non-response to a statement 
replying. While it cannot be assumed that the views of those responding mirror non-responders, the numbers involved represent approximately one third of all dentists in Wales. This work therefore provides the current views of a sizeable proportion of general dental practitioners in the Principality.

While a survey of dental provision by primary care trusts in England has been undertaken by The Patients Association, ${ }^{10}$ this study is, to our knowledge, the first comprehensive analysis of dentists' opinions in Wales. The similarities in the new contract in England and Wales are such that the main findings of this study are likely to pertain in England.

The questions used in the survey had been used in the previous precontract implementation survey ${ }^{8}$ and were regarded as fit for purpose without the need for a pilot study on this occasion. The questions had originally been devised in line with the factors known to be of concern in the reform of NHS dental services and with the stated objectives of the reforms.

This survey shows that the majority of dentists have continued to provide NHS dental services following the introduction of the new contract. However, about one quarter claim to have decreased their commitment and 7\% have increased their commitment. These data compare favourably with practitioner intentions reported in the January 2006 survey. ${ }^{8}$ At that time, 9\% indicated that they were intent on leaving the NHS following the introduction of the new contract. This matches fairly well with the 11\% recorded in the current survey and suggests that the response to these surveys with respect to future intent is reasonably accurate.

Recent reviews and commentaries of the dental workforce have made much of the changed gender balance in dental graduates - the so-called feminisation of the workforce. ${ }^{11}$ The results of this survey find that nearly a third of female respondents are significantly more likely ( $p<0.001$ ) to work for three days per week or less. Older dentists are more likely to work part-time and as shown in this study, devote less time to the NHS. The implications of these trends on patient access are at this time unknown but are worthy of further research.

The objectives of the reform of NHS dental services were clearly set out by the Department of Health ${ }^{6}$ and subsequently endorsed by the Wales Assembly Government. ${ }^{12}$ The results of this study suggest that 18 months following the introduction of the contract, dentists in Wales do not perceive the contract to have achieved many of its key objectives.

Central to the new way of working was a method of commissioning dental care whereby dentists would have more time available to spend with patients. Only 14 of the 417 dentists in this survey who continued to provide NHS dental care agreed this to be the case. This and the finding that just 15 dentists agreed that they had more time available to spend on prevention, are perhaps the two key findings of this work in terms of the overall success of the reforms. The data presented in Table 4 indicate that the majority of dentists do not perceive the new contract to allow prioritisation of care or freedom in clinical decisions. The much vaunted introduction of preventive roles such as smoking cessation has been implemented by only a minority of practitioners. In the opinion of the dentists replying to this survey, freeing up time for a more preventive approach, removal of the 'treadmill' and the removal of outmoded treatment incentives have not been achieved.

A recurring criticism of the previous 'fee-for-item' mechanism for remunerating NHS dentists was the treadmill effect. ${ }^{1,2}$ The present study suggests that dentists still feel they are on a treadmill, albeit of a different nature. Previously the issue was one of working to make money to keep their practice viable. Now the fear is one of penalty, striving to achieve contract targets and prevent monies being clawed back by the contracting authorities.

Only one in ten agreed that they liked the new method of remuneration. Units of dental activity (UDAs) are disliked as a contract currency and in the open comments in response to the questionnaire, there was much criticism of the UDA banding system and the perceived inequities resulting.
The inability to charge patients who fail to attend appointments is a major source of frustration. Evidence from a representative survey of the general public in Wales suggests that the majority think that it is reasonable for dentists to charge patients who do not attend with giving reasonable notice. ${ }^{13}$ This aspect of the contract could be modified, would be popular with dentists and is something that patients have been used to. However, while the inability to charge patients for broken appointments is also a source of frustration, problems with patient charges are fewer than had been anticipated.

The survey participants are in general happy with their surgery environment, although lack of adequate information technology provision was an issue for almost one third. Having sufficient time available for continuing professional development, audit and administration is a major issue.

It is possible that perspectives on the new contract may differ between those providing care as a provider or performer. It was not the specific objective of this study to examine this aspect of the revised contracting arrangements. However, in relation to two of the key objectives of the reforms, ie elimination of the treadmill and the introduction of a new system of remuneration, the responses to this survey suggest that there was no difference in perception of the effect of the new contract on these issues between performers and providers. The percentage of performers and associates was very similar between the two surveys, with $37.5 \%$ declaring themselves solely performers in the second survey compared with 39.3\% being associates in the previous pre-contract implementation survey. ${ }^{8}$

Although some personal dental service (PDS) contracts were in operation in Wales in April 2006, respondents in this survey were not asked about whether they had been contracting under PDS or conventional general dental service (GDS) arrangements at that time. However, the number of active PDS contracts in Wales in April 2006 formed a very small proportion of contracts.

In conclusion, this survey has provided a detailed summary of dentists' 
views on the new contract. It is apparent that while issues around NHS dentistry being delivered on a treadmill, the lack of opportunity for preventive interventions and concerns over outmoded treatment interventions remain, fears over complaints about patient charges, a major concern on the pre-implementation phase, have not materialised.

As the mechanism for contracting for primary dental care evolves, government, local commissioners and dentists will need to consider these findings. Future contract developments need to address the perceived deficiencies identified by this study.
The authors wish to express their thanks to the practitioners who gave of their time to complete and return the questionnaire. The work was funded by the Local Health Boards in Wales whose assistance is acknowledged gratefully.

1. Audit Commission. Dentistry. Primary dental care services in England and Wales. London: Audit Commission, 2002.

2. Bloomfield K. Fundamental review of dental remuneration. London: HMSO, 1992

3. Department of Health. NHS dentistry: options for change. London: Department of Health, 2002.

4. Schanschieff S G, Shovelton D S, Toulmin J K. Report of the committee of enquiry into unnecessary dental treatment. London: HMSO, 1986.

5. Wales Assembly Government. Routes to reform: a strategy for primary dental care in Wales. Cardiff: Wales Assembly Government, 2002

6. Department of Health. Primary care dental services: implementation of local commissioning. London: Department of Health, 2005.

7. Milsom K M, Threlfall A, Pine K et al.
The introduction of the new dental contract in England - a baseline qualitative assessment. $\mathrm{Br}$ Dent J 2008; 204: 59-62.

8. Chestnutt I G, Thomas D R, Patel R, Treasure ET. Perceptions and attitudes to a fundamental reform of general dental services in Wales. Primary Dent Care 2007: 14: 13-18.

9. National Institute for Clinical Excellence. Dental recall: recall interval between dental examinations. London: National Institute for Clinical Excellence, 2004. Clinical Guideline 19

10. The Patients Association. Dental report - "Full of holes and causing pain". Harrow, England: The Patients Association, 2008.

11. Ward P. The changing shape of the dental profession. Br Dent J 2008; 204: 1.

12. Wales Assembly Government. A guide to NHS primary dental services from April 2006. Cardiff: Wales Assembly Government, 2006.

13. Chestnutt I G, Thomas D R, Davies L, Jones M, Channing D. Implementing the new dental contract: studies to inform the planning of NHS general dental services in Wales. Cardiff: Cardiff University Dental School, 2008. 